\title{
Synthesis, Properties, and Biological Activity of Poly(1-vinyl-1,2,4-triazole) and Silver Nanocomposites Based on It
}

\author{
G. F. Prozorova ${ }^{a}$ and A. S. Pozdnyakov ${ }^{a, *}$ \\ ${ }^{a}$ Irkutsk Institute of Chemistry, Siberian Branch, Russian Academy of Sciences, Irkutsk, 664033 Russia \\ *e-mail:pozdnyakov@irioch.irk.ru
}

Received April 5, 2021; revised December 8, 2021; accepted December 22, 2021

\begin{abstract}
The review summarizes the data on the synthesis, physicochemical properties, and biological activity of poly(1-vinyl-1,2,4-triazole) and its nanocomposites with silver nanoparticles. The results of studying the antibacterial and antitumor activity of the polymers and nanocomposites and their immunomodulatory ability, toxicity, and interaction with body cells, as well as the prospects for their use in the development of medical materials, are presented.
\end{abstract}

DOI: $10.1134 / \mathrm{S} 1811238222010015$

The increasing demand of modern medicine and pharmaceutics for effective biologically active materials contributes to the intensified creation of novel functional polymeric metal-containing nanocomposites promising for designing antibacterial and immunomodulatory drugs and systems for the targeted delivery of contrast agents, drugs, modifiers, and biosensors. These materials should possess important properties, such as the pharmacological activity, hydrophilicity, nontoxicity, biocompatibility, and aggressive media resistance, as well as the possibility of binding with various compounds, including drugs.

Polymers can effectively stabilize nanoparticles, thereby preventing their aggregation, increase water solubility, and enhance the biological activity of nanocomposites [1-8]. For example, synthetic and natural polymers, polyvinylpyrrolidone, polyacrylamide, poly(vinyl alcohol), chitosan, and arabinogalactan, are used as matrices for biologically active nanocomposites [1,9-21]. When designing high-tech materials considerable attention is also given to functional polymers bearing nitrogen-containing heterocyclic fragments providing the diversity of properties valuable for practice. Among nitrogen-containing polymers watersoluble 1-vinyl-1,2,4-triazole homopolymers and copolymers have gained special interest. They possess a whole set of properties important for practice: high hydrophilicity, solubility in dipolar organic solvents, complexation and quaternization ability, chemical resistance, biocompatibility, and thermal stability. Triazole-containing polymers behave as effective stabilizing matrices in the formation of metal-containing nanocomposites, manifesting synergy of the unique properties of polymers (solubility, biocompatibility, high coordination ability) and optical, catalytic, and biological properties of metal nanoparticles [22-25].

Owing to the appearance of various strains of gram-positive and gram-negative bacteria resistant to antibiotics an increasing attention is given to silvercontaining drugs. Silver nanoparticles demonstrate antimicrobial, immunomodulatory, and antiviral activity and, therefore, act as effective agents against many pathogenic human viruses, such as the respiratory syncytial virus, hepatitis B virus, norovirus, human immunodeficiency virus, and coronavirus COVID-19 [26-28]. The biological activity of nanosized particles depends on various factors with size, shape, concentration, and surface charge being the main ones [29]. Functional polymers can ensure control over parameters of the nanosized phase and its effective stabilization at early formation stages which defines the behavior of these systems. Polymeric nanocomposites with silver nanoparticles exhibit a broad biological activity [8-33]. Note that there is the steadily growing demand on parameters of the metal nanoparticles (sizes, morphology, and aggregative stability) and properties of the polymer component (lyophilicity, biocompatibility, nontoxicity, chemical resistance, and thermal stability). Therefore, the development of novel biologically active polymeric materials is one of priority research areas in modern medicine.

This review presents results on the synthesis of 1-vinyl-1,2,4-triazole homopolymer and its nanocomposites with silver nanoparticles and the comprehensive study of their physicochemical properties and biological activity. 


\section{SYNTHESIS \\ OF POLY(1-VINYL-1,2,4-TRIAZOLE)}

The radical polymerization of 1-vinyl-1,2,4-triazole (VT) is most commonly carried out using AIBN as an initiator [33-45]. For example, the authors of [38] studied the kinetics of radical polymerization in various solvents (water, DMF, DMAA) by dilatometry, calorimetry, and gravimetry. The reaction was conducted at a temperature of $50-90^{\circ} \mathrm{C}$ at varying concentrations of AIBN $\left(1 \times 10^{-3}-3 \times 10^{-2} \mathrm{~mol} / \mathrm{L}\right)$ and VT $(0.5-0.6 \mathrm{~mol} / \mathrm{L})$. Regardless of the solvent nature, the kinetic curves had the $S$-shaped pattern. The length of the induction period was independent of the concentration of VT and inversely proportional to the initiator concentration. This probably results from inhibition of the polymerization process by the traces of oxygen whose removal from the polar solvent is hardly possible. The rate of VT polymerization and the molecular weight of the polymer in water are higher than those in DMF and DMAA. In dipolar solvents, polymerization rates are almost equal. According to [38], the molecular weight of the resulting poly(1vinyl-1,2,4-triazole) (PVT) is independent of initiator concentration. The intrinsic viscosity of PVT synthesized in water is 3.5 times higher than that in DMAA. It was shown that the introduction of water (above $0.05 \mathrm{~mol} / \mathrm{L}$ ) into polymerization carried out in DMF and DMAA causes a rise in the MW of the polymer. The authors of [38] believe that this effect can be explained by an increase in the reactivity of VT owing to the specific solvation of a monomer and growing macroradical by water. The hydration of a growing polymer radical can influence its reactivity, slowing down rate of the bimolecular chain termination reaction, as in the polymerization of $N$-vinylamides [39]. This circumstance can be attributed to a change in charge on a terminal carbon atom or presence of the hydrate layer near the radical. Therefore, the approach of terminal radicals belonging to different molecular chains will be hindered due to the electrostatic repulsion of like charges or the necessity to displace hydrate layers.

The special feature of the radical polymerization of VT is the first reaction order with respect to the monomer concentration. The reaction order with respect to the initiator concentration decreases in the sequence DMAA $<\mathrm{H}_{2} \mathrm{O}<$ DMF from 1.0 to 0.8 , as is typical of degradation chain transfer to the monomer or polymerization inhibition. According to the obtained experimental data it can be stated that, in the radical polymerization of VT, the kinetic features are related to both bimolecular and unimolecular (to a higher extent) mechanisms of macroradical termination [38].

The authors of [40] performed the EPR study using 2-methyl-2-nitrosopropane (BuNO) as a spin trapping agent and managed to validate the unimolecular termination mechanism of growing macroradicals through identification of growing chain radicals and 1,2,4-triazole:
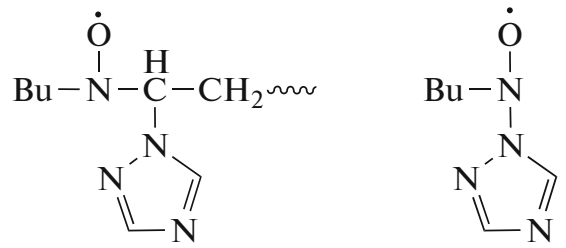

Polymerization carried out in the aprotic solvent, acetonitrile, in the presence of AIBN proceeds as a stationary process without any induction period, and initial rate values depend on reagent concentration and temperature. The initiator concentration indicates the fractional order of the reaction $(0.5)$ which is evidence for the bimolecular termination of a growing chain. In contrast to polymerization in dipolar solvents (DMF, DMAA) and water, in the case of acetonitrile, the MW of the polymer depends on initiator concentration. Upon the introduction of water into polymerization the reaction rate and molecular weight increase [41].

Since VT is a weak base $\left(\mathrm{p} K_{\mathrm{BH}^{+}}=3.11\right)$, the kinetic parameters of the polymerization reaction will probably depend on the $\mathrm{pH}$ of a medium. For example, the authors of [42] showed that the rate of reaction is described by an extremal curve with a minimum at $\mathrm{pH} \sim 7$. Reduction in $\mathrm{pH}$ from 7 to 3 leads to an increase in the rate of reaction, which is promoted by triazole ring protonation, and, accordingly, enhances electron-acceptor properties of the triazole ring and radical of a growing macromolecule. The increase in $\mathrm{pH}$ from 7 to 10 also causes acceleration of polymerization which is apparently associated with the donoracceptor interaction of the pyridine nitrogen atom of the triazole ring with the alkali metal cation; this effect, by analogy with protonation in acidic media, is responsible for a rise in the polymerization activity of VT [43].

As opposed to the radical polymerization of VT in an aqueous medium, in electrochemical polymerization, the rate of the process is lower, although 1-ethyl1,2,4-triazole is the key product of electrolysis. The latter is formed through the hydrogenation of VT by hydrogen evolving during the partial hydrolysis of water. When electrolysis is conducted in bulk or DMF 1-vinyl-1,2,4-triazole is not reduced to the ethyl derivative and the yield of PVT with $M=(2.8-5.3) \times 10^{5}$ is not above $4 \%$. The electrolysis of VT proceeds much easier in the presence of easily reducible compounds, for example, potassium persulfate, which is known to initiate the polymerization of vinyl compounds. Upon addition of a small amount of these compounds the yield of the polymer with $M=6 \times 10^{5}$ grows to $70 \%$.

It should be emphasized that polymerization occurs both in the near-electrode layer and in the bulk $[44,45]$. Depending on current density the electrochemical polymerization of VT affords different reac- 
tion products: at a small current density (up to $450 \mathrm{~mA} / \mathrm{cm}^{2}$ ) PVT is produced, while at larger current densities (450-2000 $\mathrm{mA} / \mathrm{cm}^{2}$ ) polyconjugated structures are synthesized. The copolymers contain two types of units formed via vinyl group and triazole ring opening:

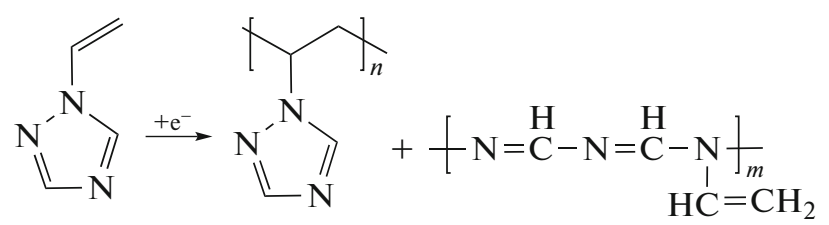

As the current density is increased above $2000 \mathrm{~mA} / \mathrm{cm}^{2}$ black graphite-like polymers are formed owing to secondary reactions involving double bonds of the vinyl group [45].

PVT synthesized by radical polymerization is a white powder well soluble in water and acetic acid and polar solvents DMF, DMSO, and DMAA.

\section{PROPERTIES \\ OF POLY(1-VINYL-1,2,4-TRIAZOLE)}

Poly(1-vinyl-1,2,4-triazole) is a hydrophilic polymer; its aqueous solutions were investigated in [46-48]. PVT possesses a high thermodynamic flexibility in water; its Kuhn segment is $3.3 \mathrm{~nm}$ [46]. Concentration dependences of the heat of dilution of PVT solutions are characterized by negative effects which attests to a strong interaction of PVT with water. The absolute values $(\mathrm{kcal} / \mathrm{mol})$ of enthalpy, entropy $(T \Delta S)$, and free energy of mixing PVT with water are $\Delta H=-68.9, T \Delta S=-31.1$, and $\Delta G=-37.8$, respectively. It appears that the exothermic heat effect is associated with a strong interaction of PVT units with water molecules resulting from the formation of hydrogen bonds involving unshared electron pairs of nitrogen atoms of triazole rings. Thus, when interacting with water PVT acts as an electron donor and demonstrates basic properties [47].

In order to gain insight into the nature of hydration the authors of [48] examined the heat capacity of dilute aqueous solutions of PVT and the water diffusion coefficient in its films. The data obtained suggest that hydrophilic hydration occurs due to the interaction of water hydrogen atoms with the unshared electron pair of the "pyridine" nitrogen atom of the hetero ring [48].

The authors of [49] investigated the thermochemical behavior of PVT solutions in strongly polar solvents DMF (the donor number, 26.6; the acceptor number, 16.0), DMAA (the donor number, 27.8; the acceptor number, 13.6), and methylpyrrolidone (the donor number, 27.3; the acceptor number, 13.3). PVT was indefinitely soluble in all of the three solvents. It was shown that dissolution of the polymer is accompanied by large exothermic effects. During interaction with PVT the above solvents act as electron donors (high donor numbers) while PVT behaves as an elec- tron acceptor. The acceptor behavior of PVT is related to the presence of the aromatic ring in its composition; i.e., PVT is an amphoteric compound in its nature. For the same reason PVT is soluble in DMSO (the donor number, 29.8; the acceptor number, 19.3).

In addition to donor solvents, PVT is soluble in strong acceptor solvents, such as acetic acid and formic acid. Here, it behaves, as in the case of water, as a donor. In such solvents as acetone, tetrahydrofuran, acetonitrile, alcohol, dioxane, heptane, nitromethane, diethyl ether, and dichloroethane, PVT is insoluble.

The hydrodynamic properties of PVT solutions in water and DMF were investigated by viscometry and light scattering, and constants $K$ and $\alpha$ in the KuhnMark-Houwink-Sakurada equation were determined [46]. Relations between the [ $\eta$ ] of PVT at $25^{\circ} \mathrm{C}$ and its $M_{\mathrm{w}}$ were as follows: in water, $[\eta]=5.44 \times 10^{-4} \times$ $M_{\mathrm{w}}^{0.64} \mathrm{dL} / \mathrm{g}$; in DMF, $[\eta]=2.27 \times 10^{-3} \times M_{\mathrm{w}}^{0.5} \mathrm{dL} / \mathrm{g}$.

The polymer is sufficiently stable hydrolytically, is not subject to thermo-oxidative degradation (up to $360^{\circ} \mathrm{C}$ ) [50], and can form complexes with metal ions [51]; therefore, it can effectively be used for the development of an aqueous quenching medium and flocculants for juice and wine clarification and stabilization [52-55].

PVT is a weak amphoteric polyelectrolyte for which donor properties can be defined by the nitrogen atom in position 4 of the triazole ring, while its acceptor properties can be defined by the $\pi$-conjugated system in a chain. Addition of low molecular weight salt $\mathrm{NaCl}$ to PVT solutions increases its basicity and simultaneously decreases acidity. Upon neutralization of PVT solution with acid by 5 to $6 \%$ basicity decreased by two to three orders of magnitude [56]. Taking into consideration the above evidence on the donor-acceptor interaction in the PVT aqueous solution it likely that triazole units can behave as both donors and acceptors with respect to each other, thereby enhancing basicity:

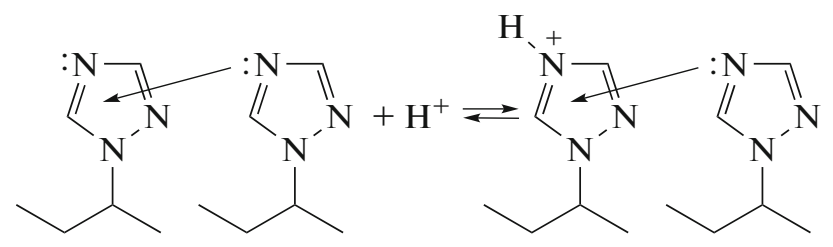

An increase in the positive charge on a polymer chain upon addition of a small amount of acid entails the rupture of bonds between triazole fragments; as a result, basicity decreases sharply.

The unusual behavior of the solution $\mathrm{pH}$ curve is observed after addition of a small amount of bases ( $\mathrm{LiOH}, \mathrm{NaOH}, \mathrm{KOH})$. Titration curves for PVT solution are initially situated below the corresponding curves for pure alkali solutions and subsequently shift to a more basic region. This tendency can be explained by the interaction of triazole rings with cations and anions of dissociated hydroxides: 


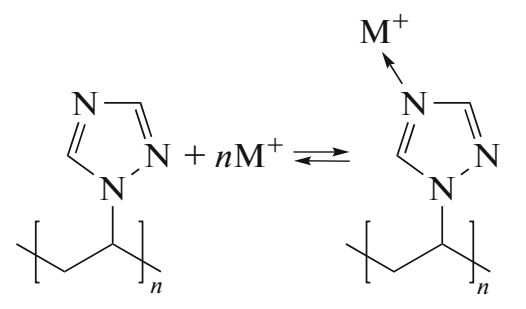

Introduction of a low molecular weight salt leads to the shift of titration curves to the alkaline region. This can apparently be attributed to the competing reactions of triazole ring interaction with anions; as a result, the concentration of hydroxyl groups in solution grows. As the charge on a macromolecule is increased (addition of acid or alkali), its rigidity is enhanced and conformation changes to a more unfolded one which is accompanied by an increase in viscosity [56].

PVT is a water-soluble, biocompatible, and nontoxic $\left(\mathrm{LD}_{50}>5000 \mathrm{mg} / \mathrm{kg}\right.$, peroral administration) polymer with $M=10^{4}-10^{6}$ showing the biological activity. The polymer exhibits antisilicotic properties, protects cell membranes from the cytotoxic action of silica during dust interaction with erythrocyte and celiac macrophage cells, and demonstrates protective functions in dust fibrosis [55]. PVT improves the activity of cells, stimulates the development of granulation fibrous tissue, and contributes to the activity of connective tissue capsule cells [57].

In recent years, the ability of VT homopolymer and copolymers to stabilize metal nanoparticles during the formation of novel polymeric metal-containing nanocomposites has been studied intensively [58-63]. Meaningful results were reported for the biological activity of polymeric nanocomposites with silver nanoparticles.

\section{FEATURES OF THE FORMATION OF POLYMERIC SILVER NANOCOMPOSITES}

For the synthesis of polymeric nanocomposites with zero-valent silver nanoparticles PVT with $M=$ $26 \times 10^{3}$ showing good solubility in water, high thermal stability (up to $330^{\circ} \mathrm{C}$ ), biocompatibility, and nontoxicity was used as a stabilizing matrix. In the solid state, the polymer is X-ray amorphous and has a "cellular" structure (Fig. 1a). According to photon correlation spectroscopy, PVT macromolecules occur in an aqueous solution as statistical coils with an average hydrodynamic diameter of $292 \mathrm{~nm}$ (Fig. 1b) [64].

Metal silver nanoparticles were formed in a polymer matrix by the chemical reduction of silver ions from silver nitrate using sodium borohydride, glucose, or formaldehyde as reducers [65-67]. The reaction was carried out in a PVT aqueous solution at varying reaction time, temperature, and polymer-to-metal precursor ratio. Formation of metallopolymer nano-

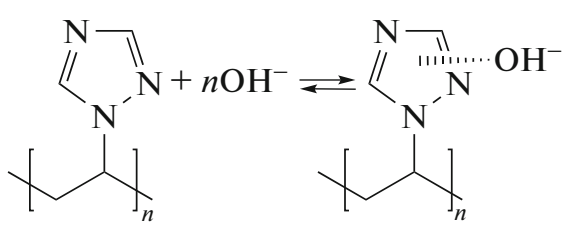

composites proceeds through complexation of PVT with silver ions accompanied by an increase in solution viscosity and appearance of gel-like suspensions [68]. This is due to the specific coordination crosslinking between linear PVT macromolecules where silver ions act as a coordination crosslinking agent:

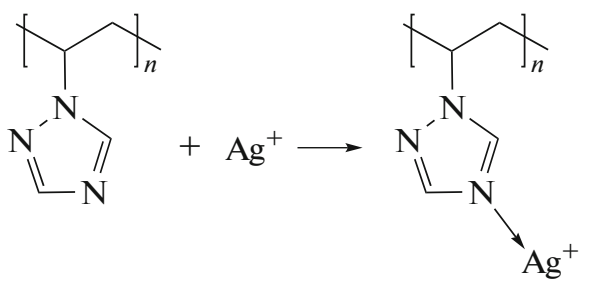

The latter have the coordination number 2 (or above) and simultaneously can form several (two as a minimum) coordination bonds with triazole rings both within one polymer molecule and between macromolecules. Polymer complexes are formed owing to the donor-acceptor interaction of silver cations with nitrogen atom in position 4 of the triazole ring [68].

Upon subsequent addition of a reducer (sodium borohydride, glucose, or formaldehyde) silver cations are reduced to the metal state. In the presence of PVT coordinating macromolecules, nanoparticles are incorporated into macromolecules to afford complex nanocomposite particles in which metal nanoparticles are held in the PVT macromolecular matrix by coordination bonds formed between triazole rings and surface silver atoms. Given this, the resulting bond between silver nanoparticles and PVT matrix will be strengthened many times owing to cooperative multipoint coordination bonding. The hydrodynamic diameter of such complex nanocomposite particles decreases relative to that of initial PVT macromolecules (from $292 \mathrm{~nm}$ for PVT to $195 \mathrm{~nm}$ for PVT-based nanocomposites). This trend can be rationalized by the fact that relatively loose macromolecular coils of initial polymer molecules, which are fairly unfolded in an aqueous solution, undergo compaction due to a denser folding of coils under the impact of multiple cooperative forces of coordination crosslinking performed by silver nanoparticles. An increase in the concentration of silver nanoparticles leads to the formation of an insoluble crosslinked nanocomposite which is observed at the silver content above $10 \%$. The effect of reduction in the solubility of nanocomposites with a high content of silver is contributed by an increasing contribution (with an increase in the content of silver) of the reaction of complexation of surface atoms of sil- 
(a)

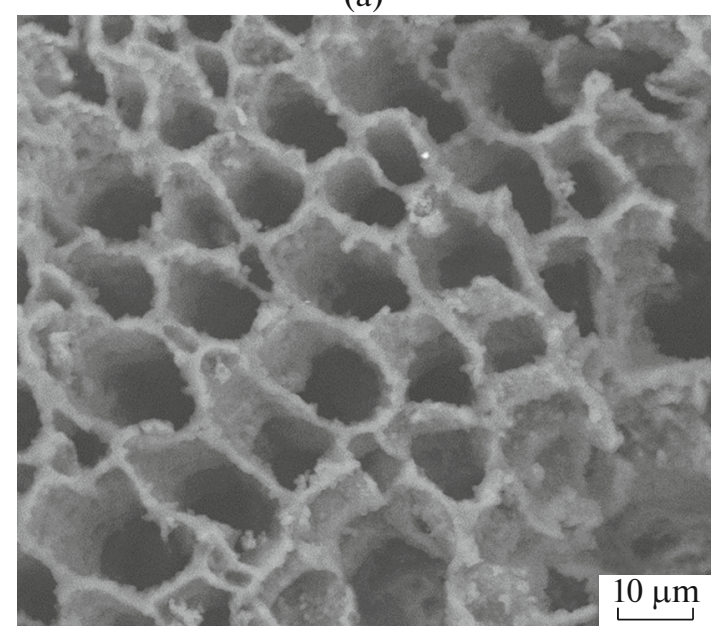

(b)

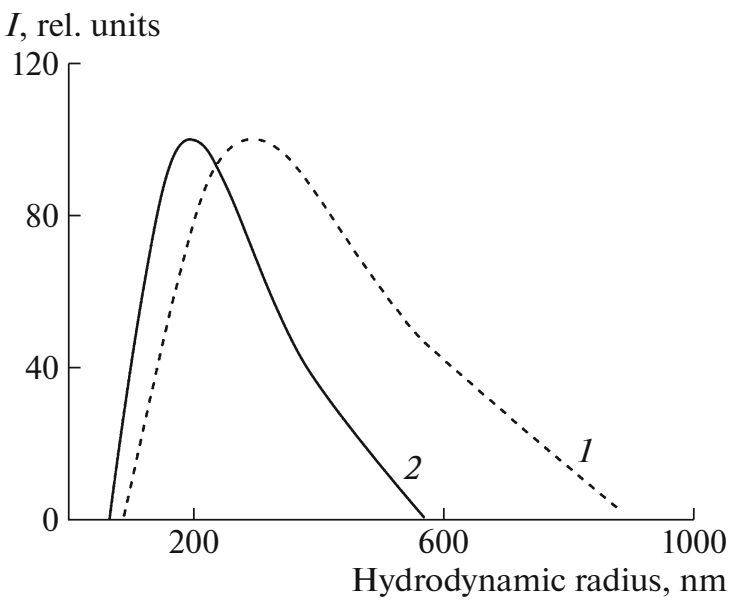

Fig. 1. (a) SEM image of PVT and (b) particle size distribution curves of (1) the initial PVT and (2) the nanocomposite with silver nanoparticles.

ver nanoparticles with triazole rings which in this case competes with the process of polymer hydration. Thus, at a high content of silver alternative complex formation reactions involving triazole hetero rings may become prevailing over the hydration of PVT macromolecules [57]. Therefore, with an increase in the content of silver nanocomposites first partially and then completely lose solubility in all accessible solvents. The reaction is completed by the appearance of brown sols from which nanocomposites are isolated in the form of dark brown powders (Table 1).

Variation in reaction conditions allowed the synthesis of novel polymeric nanocomposites with different content (1.8-20.8\%) and size (2-26 nm) of silver nanoparticles uniformly distributed in the polymer matrix (Table 1).

In contrast to the aqueous solutions of initial silver nitrate and PVT, characteristic plasmon resonance absorption (PRA) bands corresponding to the conduction electrons of silver metal nanoparticles emerge in the optical absorption spectra of nanocomposite aqueous solutions with a maximum in the range of 409-433 $\mathrm{nm}$ when using sodium borohydride as a reducer (Fig. 2a). It should be noted that there are no bands in the spectrum of PVT in the range from 300 to $700 \mathrm{~nm}$. When glucose and formaldehyde are used as reducers, the maxima of PRA bands can be seen at 418 and $426 \mathrm{~nm}$, respectively (Fig. 2b).

The X-ray diffractograms of the nanocomposites clear show amorphous halo of the polymer matrix and intense reflections of the zero-valent metal silver (Fig. 3) which were identified by comparing the values of interplanar distances and relative intensities with the standard values available for metal silver.

The synthesized silver nanoparticles are mostly spherical in shape, and their sizes and polydispersity depend on the reducer nature (Fig. 4).

In the case of a strong reducer $\mathrm{NaBH}_{4}$, silver nanoparticles in the polymer matrix are characterized by a narrow polydispersity: $92 \%$ particles have sizes

Table 1. Synthesis conditions and properties of the nanocomposites with silver nanoparticle in the PVT matrix

\begin{tabular}{|c|c|c|c|c|c|c|}
\hline Nanocomposite & $\begin{array}{l}\text { Polymer : } \\
\mathrm{AgNO}_{3} \text {, } \\
\mathrm{mol} / \mathrm{mol}\end{array}$ & Reducer & $\begin{array}{c}\text { Content } \\
\text { of } \mathrm{Ag}, \text { wt \% }\end{array}$ & $\begin{array}{c}\text { Size of Ag } \\
\text { nanoparticles, } \\
\mathrm{nm}\end{array}$ & Yield, \% & $\begin{array}{c}\text { Solubility in } \\
\mathrm{H}_{2} \mathrm{O}\end{array}$ \\
\hline 1 & $50: 1$ & $\mathrm{NaBH}_{4}$ & 1.8 & $2-8$ & 80 & + \\
\hline 2 & $20: 1$ & $\mathrm{NaBH}_{4}$ & 5.0 & $2-10$ & 84 & + \\
\hline 3 & $15: 1$ & $\mathrm{NaBH}_{4}$ & 10.1 & $2-10$ & 86 & + \\
\hline 4 & $10: 1$ & $\mathrm{NaBH}_{4}$ & 13.6 & $2-10$ & 82 & $+1-$ \\
\hline 5 & $5: 1$ & $\mathrm{NaBH}_{4}$ & 20.8 & $2-12$ & 87 & - \\
\hline 6 & $20: 1$ & Formaldehyde & 3.9 & $2-14$ & 81 & + \\
\hline 7 & $20: 1$ & Glucose & 5.0 & $2-26$ & 79 & + \\
\hline
\end{tabular}



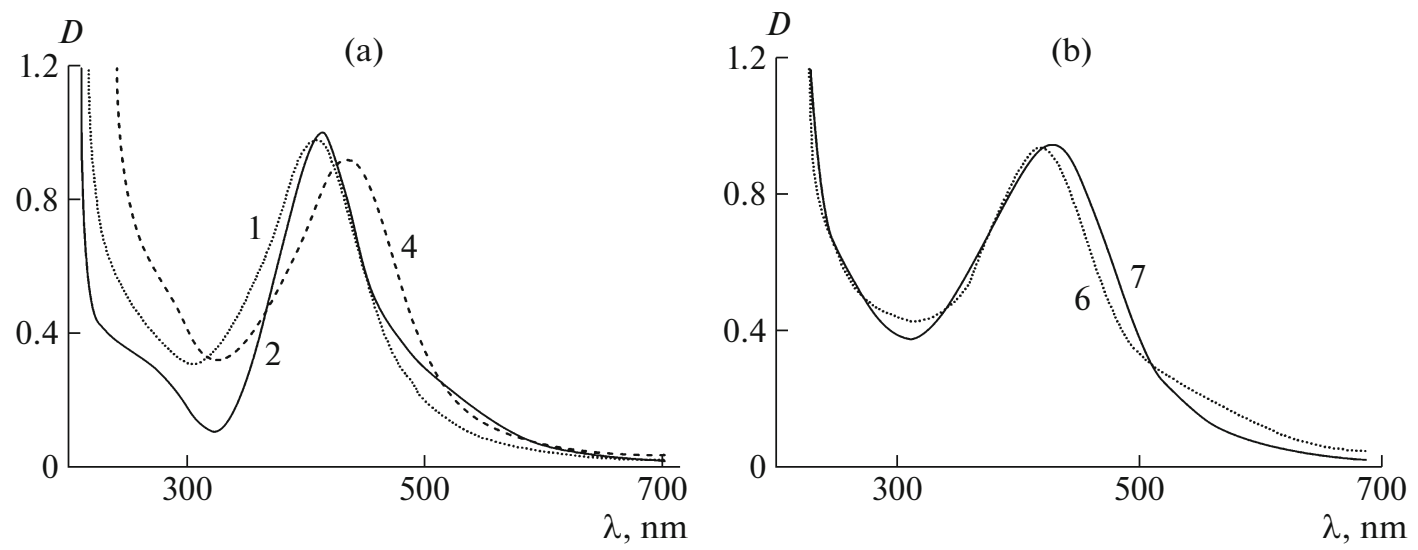

Fig. 2. Absorption spectra of the aqueous solutions of nanocomposites (a) 1, 2, and 4 and (b) 6 and 7 . The numbering of spectra corresponds to the numbering of nanocomposites in Table 1.

2-6 $\mathrm{nm}$. When glucose (a weak reducer) was used, nanoparticles with sizes up to $26 \mathrm{~nm}$ and a wider polydispersity were formed.

The thermal stability of the polymeric nanocomposites decreases by $50-70^{\circ} \mathrm{C}$ relative to the thermal stability of the initial PVT. This effect can be attributed to the catalytic features of silver nanoparticles responsible for reduction in the activation energy of thermal degradation and oxidation of the polymer matrix.

\section{ANTIMICROBIAL ACTIVITY OF NANOCOMPOSITES BASED ON POLY(1-VINYL-1,2,4-TRIAZOLE)}

The nanocomposites based on PVT and silver nanoparticles demonstrate a high antimicrobial activity with respect to various gram-negative and grampositive microorganisms [63,69, 70-74]. They are characterized by low values of the minimal inhibitory concentration and the minimal bactericidal concentration (Table 2).

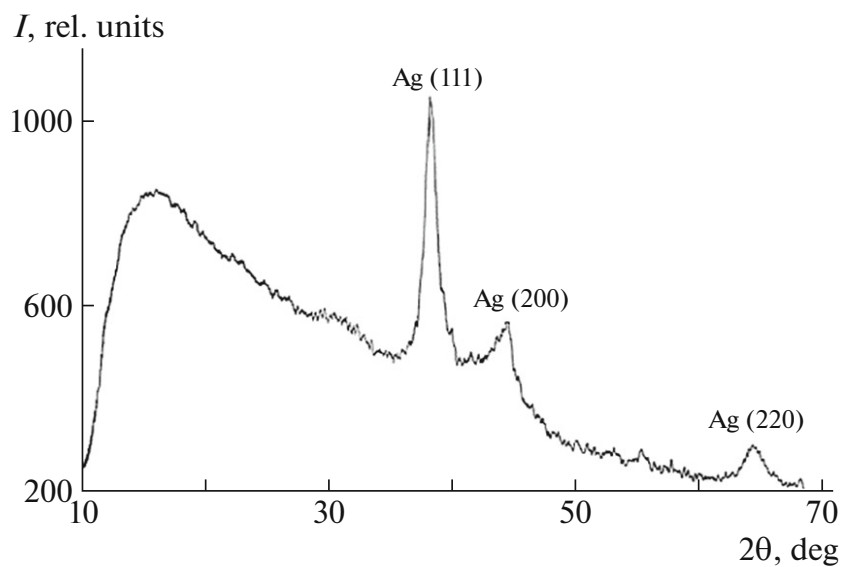

Fig. 3. Typical diffractogram of the polymeric nanocomposite.
The authors of [63] studied the mechanism behind interaction of the nanocomposite with Escherichia coli cells for 1-24 $\mathrm{h}$ and observed the processes of cytoplasm homogenization and bacteria gradual destruction [63]. During the experiment the nanocomposite and PVT remained unchanged, were not subject to biodegradation, and manifested resistance to microbial biodegradation.

\section{TOXICOLOGICAL PROPERTIES OF POLY(1-VINYL-1,2,4-TRIAZOLE) AND ITS SILVER NANOCOMPOSITES}

An important parameter of antibacterial $\operatorname{Ag}(0)$ nanomaterials is the degree of their toxicity. It was found that PVT and its nanocomposite with silver nanoparticles are nontoxic, because after incubation with specimens mammalian cells remain viable, do not change morphologically, and do not lose the ability to divide and synthesize collagen [63, 75-77]. For experimental animals there were no symptoms of intoxication and death, internal organs did not change, and hemorrhages were absent. Nanoparticles with sizes of 2-10 $\mathrm{nm}$ actively penetrated the internal organs of animals and accumulated in the tissues of kidneys $(0.19 \mu \mathrm{g} / \mathrm{kg})$, liver $(0.14 \mu \mathrm{g} / \mathrm{kg})$, and brain $(0.05 \mu \mathrm{g} / \mathrm{kg})$ [75-79]. For a long observation time (6 months) no changes indicating the activation of apoptosis in nervous cells were observed [77, 78]. The nanocomposite exhibited chemical resistance, did not degrade into separate components, did not incorporate into a chain of biological reactions in the body, and was excreted almost unchanged [77, 78]. The lethal dose $\mathrm{LD}_{50}$ for PVT and its nanocomposite with silver nanoparticles was above $5000 \mathrm{mg} / \mathrm{kg}$ [75-77]. 

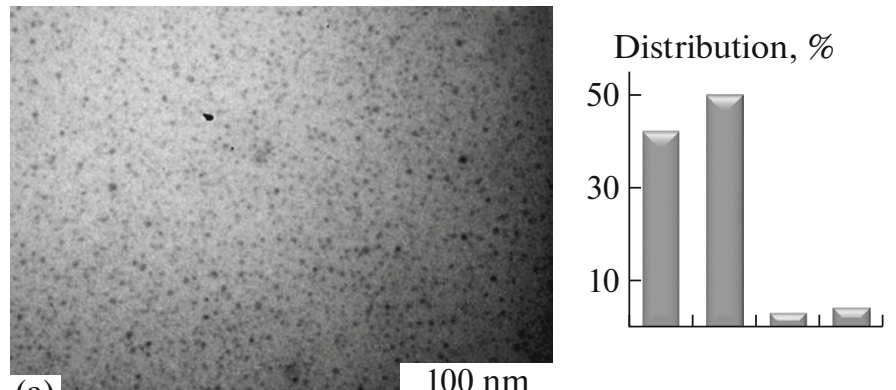

(b)
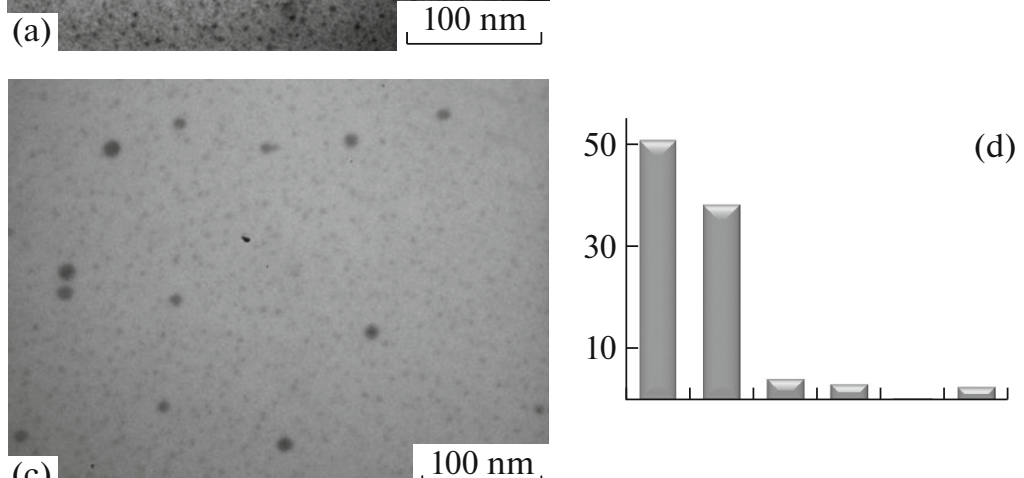

(c) $100 \mathrm{~nm}$
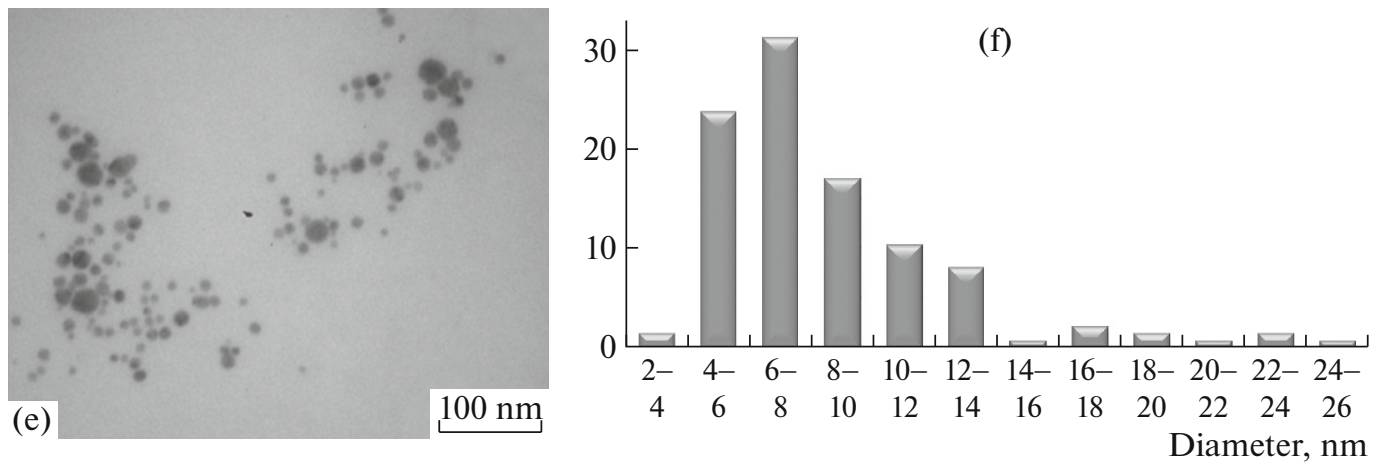

Fig. 4. (a, c, e) Micrographs of the nanocomposites and (b, d, f) size distribution diagrams of silver nanoparticles in samples synthesized using $(a, b) \mathrm{NaBH}_{4},(c, d)$ formaldehyde, and (e, f) glucose as reducers.

\section{ANTITUMOR ACTIVITY OF SILVER NANOCOMPOSITES BASED \\ ON POLY(1-VINYL-1,2,4-TRIAZOLE)}

Comprehensive studies of the cytotoxic action of the PVT-based polymeric nanocomposite on primary and transformed human cells in vitro were described in [80]. Model systems were primary endotheliocytes HUVEC from the umbilical vein of newborns, pri- mary GF fibroblasts from human gingival tissue, breast adenocarcinoma Mcf-7 cells, and cervical adenocarcinoma HeLa cells. Nanocomposite concentrations, at which the death of half of $\mathrm{TC}_{50}$ cells was observed, were determined (Table 3).

Nanocomposite NC-2 possesses toxicity for primary fibroblasts and HeLa line cells. It can accumulate in tumor lacunas and increase necrosis areas, con-

Table 2. Minimal inhibitory concentration (MIC) and minimal bactericidal concentration (MBC) of the PVT-based nanocomposite $(5.0 \% \mathrm{Ag})[63]$

\begin{tabular}{l|c|c}
\hline \multicolumn{1}{c|}{ Microorganisms } & MIC, $\mu \mathrm{g} / \mathrm{mL}$ & $\mathrm{MBC}, \mu \mathrm{g} / \mathrm{mL}$ \\
\hline Escherichia coli (ATCC 25922) & 0.5 & 1.0 \\
Pseudomonas aeruginosa (ATCC 27853) & 4.0 & 4.0 \\
Klebsiella pneumonia (ATCC 700603) & 4.0 & 8.0 \\
Enterococcus faecalis (ATCC 29212) & 4.0 & 8.0 \\
Staphylococcus aureus (ATCC 25923) & 8.0 & 16.0 \\
\hline
\end{tabular}


Table 3. The values of $\mathrm{TC}_{50}(\mathrm{mg} / \mathrm{mL})$ for nanocomposites 1 $(5 \% \mathrm{Ag})$ and $2(7.8 \% \mathrm{Ag})$

\begin{tabular}{c|c|c|c|c}
\hline \multirow{2}{*}{ Nanocomposite } & \multicolumn{4}{|c}{ Cells } \\
\cline { 2 - 5 } & HUVEC & GF & Mcf-7 & HeLa \\
\hline 1 & 0.63 & 0.27 & 2.34 & 0.86 \\
2 & 0.66 & 0.03 & 0.53 & 0.02 \\
\hline
\end{tabular}

siderably worsening conditions for the vitality of tumor cells. This nanocomposite shows promise for the development of antitumor drugs.

\section{IMMUNOMODULATORY PROPERTIES OF POLY(1-VINYL-1,2,4-TRIAZOLE) AND ITS SILVER NANOCOMPOSITES}

The development of effective immunobiological drugs is a relevant trend in medicine. Particular attention is given to biosafety, namely, development of vaccines against pathogens of especially dangerous infectious diseases [81, 82]. However, because of toxicity and negative side effects only an insignificant part of compounds possessing the immunomodulatory activity is suitable for practice [82-97]. Water-soluble PVT-based polymeric nanocomposites with silver nanoparticles are nontoxic, exhibit antibacterial and cytotoxic activity, and can be regarded as potential candidates for the design of modern effective immunomodulators $[65,69,70,75-80]$.

The authors of [86-94] performed comprehensive research into the immunomodulatory action of the mentioned nanocomposites on the immune system of experimental animals, their effect on the cellular composition of the peripheral blood and bone marrow, and the efficiency of their use for the creation of vaccines able to prevent and treat of socially dangerous infectious diseases, such as plague and anthrax. It was shown that the nanocomposites do not cause irreversible pathological changes in the parenchymal organs of laboratory animals, their leukogram, and the amount of erythrocytes and leukocytes in the peripheral blood of the tested white mice. Already at early observation times (3-7 days) the immune response in the bone marrow of animals is registered, the granulocytic and monocytic lineages of bone marrow hematopoiesis are activated, and the maturation of granulocytes and lymphocytes is stimulated, as confirmed by an increase in the content of B-lymphocytes and Thelpers in animal spleen [89]. This also provides evidence that protective properties of the body are improved. The nanocomposite stimulates generation of oxygen effective forms by phagocytes, increases the production of nitrogen oxide metabolites by a factor of 2.5 (relative to the standard), and facilitates reduction in the amount of highly toxic oxygen radicals in a cell owing to activation of the catalytic capacity of superoxide dismutase [90]. The nanocomposite demon- strates protective properties against infection caused by the virulent strain Y. Pestis I-2638 for plague-susceptible white mice. Subcutaneous administration of the nanocomposite $60 \mathrm{~min}$ before infection at a dose of 10 and $100 \mathrm{mg} / \mathrm{kg}$ facilitates the survival of 30 and $50 \%$ of infected animals, respectively. The single administration of the nanocomposite at a dose of $10 \mathrm{mg} / \mathrm{kg}$ (subcutaneously) 8 days before infection protects $89 \%$ animals against dearth [90].

Taking into consideration the ability of PVT-based nanocomposites to improve protective properties of the body [87-93] their efficiency in formation of its anthrax resistance was studied [95-102]. Cells of a system of mononuclear phagocytes and polymorphonuclear leukocytes and the antigenic preparation S-1 of strain B. Anthracis Sterne $34 F_{2}$ were used as a model. The influence of nanocomposites under in vitro and in vivo conditions on oxygen-dependent and oxygenindependent mechanisms of the bactericidal action of phagocytes in experimental animals, white mice and guinea pigs, susceptible to anthrax was investigated comprehensively. It was shown that the nanocomposites exert the stimulating effect on the energy metabolism of phagocytes and contribute to an increase in the stimulation index of oxidative burst enzymes glucose6-phosphate dehydrogenase, nicotinamide adenine dinucleotide phosphate, and myeloperoxidase, relative to the standard, by 34,46 , and $12 \%$, respectively [94]. The generation of superoxide dismutase and nitrogen oxide metabolites grows by 1.3 and 2.5 times, respectively, relative to the standard. The nanocomposites are able to increase the activity of oxidative burst enzymes, have a stimulating effect on the oxygen-independent metabolism of phagocytes, and show well-defined antioxidant properties [94].

Thus, the PVT-based polymeric nanocomposites with silver nanoparticles exhibit the immunomodulatory activity, demonstrate the protective effect against plague microbe and anthrax, show promise for the development of drugs increasing the nonspecific resistance of the body, and behave as effective immunoprophylactic agents.

The above results provide evidence for a high practical value of PVT and its nanocomposites with silver nanoparticles and reveal prospects for their use in the development of medical materials.

\section{CONFLICT OF INTEREST}

The authors declare that they have no conflicts of interest.

\section{REFERENCES}

1. A. D. Pomogailo, A. S. Rozenberg, and I. E. Uflyand, Metal Nanoparticles in Polymers (Khimiya, Moscow, 2000) [in Russian].

2. A. D. Pomogailo, Ross. Khim. Zh., No. 5, 64 (2002).

3. A. A. Zezin, Polym. Sci., Ser. C 58 (1), 118 (2016). 
4. Nanomaterials Chemistry: Recent Developments and New Directions, Ed. by C. N. R. Rao, A. Müller, and A. K. Cheetham (Wiley-VCH, Weinheim, 2007).

5. M. Gorbunova and L. Lemkina, J. Biomed. Mater. Res., Part A 104, 630 (2016).

6. A. A. Zezin, V. I. Feldman, S. S. Abramchuk, V. K. Ivanchenko, E. A. Zezina, N. A. Shmakova, and V. I. Shvedunov, Polym. Sci., Ser. C 53 (1), 61 (2011).

7. A. Bakar, V. V. De, A. A. Zezin, S. S. Abramchuk, O. Güven, and V. I. Feldman, Mendeleev Commun. 22, 211 (2012).

8. E. M. Blagitko, V. A. Burmistrov, A. P. Kolesnikov, Yu. I. Mikhailov, and P. P. Rodionov, Silver in Medicine (Nauka-Tsentr, Novosibirsk, 2004) [in Russian].

9. E. F. Panarin, Innovations 116 (6), 50 (2008).

10. Yu. A. Krutyakov, A. A. Kudrinskiy, A. Yu. Olenin, and G. V. Lisichkin, Russ. Chem. Rev. 77 (3), 233 (2008).

11. A. A. Zezin, D. I. Klimov, E. A. Zezina, K. V. Mkrtchyan, and V. I. Feldman, Radiat. Phys. Chem. 169, 108076 (2020).

12. S. Prabhu and E. K. Poulose, Int. Nano Lett. 2, 32 (2012).

13. G. Nam, B. Purushothaman, S. Rangasamy, and J. M. Song, Int. Nano Lett. 6 (1), 51 (2016).

14. D. I. Klimov, E. A. Zezina, S. B. Zezin, M. Yang, F. Wang, V. I. Shvedunov, V. I. Feldman, and A. A. Zezin, Radiat. Phys. Chem. 142, 65 (2018).

15. A. A. Zezin, Polym. Sci., Ser. A 61 (6), 754 (2019).

16. M. Gorbunova, L. Lemkina, and I. Borisova, Eur. Polym. J. 105, 426 (2018).

17. R. E. Duval, J. Gouyau, and E. Lamouroux, Nanomaterials 9 (12), 1775 (2019).

18. I. X. Yin, I. S. Zhao, M. L. Mei, E. C. Lo, J. Tang, Q. Li, L. Y. So, and C. H. Chu, Int. J. Nanomed. 15, 3207 (2020).

19. I. X. Yin, J. Zhang, I. S. Zhao, M. L. Mei, Q. Li, and C. H. Chu, Int. J. Nanomed. 15, 2555 (2020).

20. C. Das, S. S. Paul, A. Saha, T. Singh, A. Saha, J. Im, and G. Biswas, Int. J. Nanomed. 15, 9301 (2020).

21. M. Huang, K. Ye, T. Hu, K. Liu, M. You, L. Wang, and H. Qin, Int. J. Nanomed. 16, 1345 (2021).

22. A. Pozdnyakov, A. Emel'yanov, N. Kuznetsova, T. Ermakova, Y. Bolgova, O. Trofimova, A. Albanov, T. Borodina, V. Smirnov, and G. Prozorova, Synlett 27, 900 (2015).

23. N. P. Kuznetsova, T. G. Ermakova, A. S. Pozdnyakov, A. I. Emel'yanov, and G. F. Prozorova, Russ. Chem. Bull. 62, 2509 (2013).

24. T. G. Ermakova, L. P. Shaulina, N. P. Kuznetsova, L. I. Volkova, A. S. Pozdnyakov, and G. F. Prozorova, Russ. J. Appl. Chem. 85, 35 (2012).

25. G. Prozorova, N. Kuznetsova, L. Shaulina, Y. Bolgova, O. Trofimova, A. Emel'yanov, and A. Pozdnyakov, J. Organomet. Chem. 916, 121273 (2020).

26. S. Galdiero, A. Falanga, M. Vitiello, M. Cantisani, V. Marra, and M. Galdiero, Molecules 16, 8894 (2011).
27. S. S. Jeremiah, K. Miyakawa, T. Morita, Y. Yamaoka, and A. Ryo, Biochem. Biophys. Res. Commun. 533, 195 (2020).

28. C. Das, S. S. Paul, A. Saha, T. Singh, A. Saha, J. Im, and G. Biswas, Int. J. Nanomed. 15, 9301 (2020).

29. A. A. Meleshko, A. G. Afinogenova, G. E. Afinogenov, A. A. Spiridonova, and V. P. Tolstoi, Infect. Immun. 10 (4), 639 (2020).

30. M. Gorbunova, L. Lemkina, I. Lebedeva, D. Kisel'kov, and L. Chekanova, J. Mater. Sci.: Mater. Med. 28, 40 (2017).

31. O. M. Tsivileva, A. I. Perfileva, A. A. Ivanova, A. S. Pozdnyakov, and G. F. Prozorova, J. Polym. Environ. 29, 1287 (2021).

32. M. N. Gorbunova, D. M. Kisel'kov, and V. O. Nebogatikov, Russ. J. Appl. Chem. 88, 320 (2015).

33. M. Gorbunova, L. Lemkina, D. Eroshenko, and K. Gileva, Polym. Adv. Technol. 30, 336 (2019).

34. H. Hopff and M. Lippay, Makromol. Chem. 66, 157 (1963).

35. S. A. Lonza, Chem. Abstr. 62, 13270 (1965).

36. M. Lippay, J. Appl. Chem. 15 (3), 310 (1965).

37. L. A. Tatarova, T. G. Ermakova, V. A. Lopyrev, and N. F. Kedrina, Byull. Izobret., No. 6, 85 (1979).

38. L. A. Tatarova, T. G. Ermakova, Al. Al. Berlin, E. F. Razvodovskii, V. A. Lopyrev, N. F. Kedrina, and N. S. Enikolopyan, Vysokomol. Soedin., Ser. A 24 (10), 2205 (1982).

39. Yu. E. Kirsh, Poly-N-vinylpyrrolidone and Other Poly$N$-vinylamides: Synthesis and Physicochemical Properties (Nauka, Moscow, 1998) [in Russian].

40. V. A. Lopyrev, L. A. Tatarova, T. I. Vakul'skaya, and T. G. Ermakova, Vysokomol. Soedin., Ser. B 27 (3), 221 (1985).

41. N. A. Tsypina, V. N. Kizhnyaev, F. A. Pokatilov, and A. I. Smirnov, Polym. Sci., Ser. B 45 (1-2), 41 (2003).

42. V. N. Kizhnyaev, N. A. Tsypina, and A. I. Smirnov, Polym. Sci., Ser. A 45 (8), 735 (2003).

43. N. L. Mazyar, Candidate's Dissertation in Chemistry (Irkutsk, 1999).

44. V. A. Lopyrev, T. N. Kashik, L. E. Protasova, T. G. Ermakova, and M. G. Voronkov, Vysokomol. Soedin., Ser. B 26 (8), 594 (1984).

45. V. A. Lopyrev, T. N. Kashik, T. G. Ermakova, and E. I. Brodskaya, Vysokomol. Soedin., Ser. A 32 (1), 149 (1990).

46. L. A. Tatarova, T. G. Ermakova, N. F. Kedrina, V. A. Kasaikin, D. D. Novikov, and V. A. Lopyrev, Vysokomol. Soedin., Ser. B 24 (9), 697 (1982).

47. A. A. Tager, A. P. Safronov, V. A. Lopyrev, T. G. Ermakova, L. A. Tatarova, and T. N. Kashik, Vysokomol. Soedin., Ser. A 29 (11), 2421 (1987).

48. A. P. Safronov, A. A. Tager, S. V. Sharina, V. A. Lopyrev, T. G. Ermakova, L. A. Tatarova, and T. N. Kashik, Vysokomol. Soedin., Ser. A 31 (12), 2662 (1989).

49. A. P. Safronov, A. A. Tager, V. V. Voit, V. A. Lopyrev, T. G. Ermakova, L. A. Tatarova, and N. S. Shaglaeva, Vysokomol. Soedin., Ser. A 30 (11), 2360 (1988). 
50. V. A. Lopyrev, V. N. Salaurov, V. N. Kurochkin, L. A. Tatarova, and T. G. Ermakova, Vysokomol. Soedin., Ser. B 27 (2), 145 (1985).

51. A. I. Kokorin, A. S. Polinskii, V. S. Pshezhetskii, N. P. Kuznetsova, T. G. Ermakova, V. A. Lopyrev, and V. A. Kabanov, Vysokomolekul. Soed., Ser. A 27 (9), 1834 (1985).

52. M. G. Voronkov, V. A. Lopyrev, E. V. Kukharskaya, T. G. Ermakova, and L. A. Tatarova, Zh. Prikl. Khim. (S.-Peterburg, Russ. Fed.) 58 (1), 190 (1985).

53. V. I. Zinchenko, A. S. Makarov, V. A. Lopyrev, T. G. Ermakova, and L. A. Tatarova, Pivo Napitki, No. 4, 58 (1999).

54. V. I. Zinchenko, A. S. Makarov, V. A. Lopyrev, T. G. Ermakova, and L. A. Tatarova, Storage Process. Agric. Prod., No. 3, 29 (2000).

55. T. G. Ermakova and N. P. Kuznetsova, Nauka Proizvod., No. 6, 55 (2003).

56. N. L. Mazyar, V. V. Annenkov, and V. A. Kruglova, Izv. Akad. Nauk, Ser. Khim., No. 12, 2047 (2000).

57. L. A. Mansurova, A. B. Skornyakova, N. A. Sevast'yanova, L. A. Tatarova, T. G. Ermakova, V. A. Lopyrev, V. B. Kazimirovskaya, and L. I. Slutskii, Khim.-Farm. Zh., No. 8, 22 (1991).

58. A. A. Zezin, A. I. Emel'yanov, G. F. Prozorova, E. A. Zezina, V. I. Feldman, S. S. Abramchuk, and A. S. Pozdnyakov, Mendeleev Commun. 29, 158 (2019).

59. A. S. Pozdnyakov, A. A. Ivanova, A. I. Emel'yanov, Y. I. Bolgova, O. M. Trofimova, and G. F. Prozorova, J. Organomet. Chem. 922, 121352 (2020).

60. T. Farooq, Advances in Triazole Chemistry (Elsevier, Amsterdam, 2021), p. 223.

61. E. A. Zezina, A. I. Emel'yanov, A. S. Pozdnyakov, G. F. Prozorova, S. S. Abramchuk, V. I. Feldman, and A. A. Zezin, Radiat. Phys. Chem. 158, 115 (2019).

62. A. S. Pozdnyakov, A. A. Ivanova, A. I. Emel'yanov, and G. F. Prozorova, Russ. Chem. Bull. 69, 715 (2020).

63. T. Farooq, Advances in Triazole Chemistry (Elsevier, Amsterdam, 2021), p. 143.

64. I. A. Shurygina, G. F. Prozorova, I. S. Trukhan, S. A. Rorzhova, T. V. Fadeeva, A. S. Pozdnyakov, N. N. Dremina, A. I. Emel'yanov, N. P. Kuznetsova, and M. G. Shurygin, Nanomaterials 10, 1477 (2020).

65. G. F. Myachina, S. A. Korzhova, T. G. Ermakova, B. G. Sukhov, and B. F. Trofimov, Dokl. Chem. 420, 123 (2008).

66. G. F. Prozorova, S. A. Korzhova, T. V. Kon'kova, T. G. Ermakova, A. S. Pozdnyakov, B. G. Sukhov, K. Yu. Arsent'ev, E. V. Likhoshvai, and B. A. Trofimov, Dokl. Chem. 437 (1), 47 (2011).

67. G. F. Prozorova, S. A. Korzhova, T. V. Kon'kova, T. G. Ermakova, A. S. Pozdnyakov, A. N. Sapozhnikov, O. A. Proidakova, B. G. Sukhov, K. Yu. Arsent'ev, E. V. Likhoshvai, and B. A. Trofimov, Zh. Strukt. Khim. 51, 109 (2010).

68. N. I. Tikhonov, S. S. Khutsishvili, L. I. Larina, A. S. Pozdnyakov, A. I. Emel'yanov, G. F. Prozorova, A. V. Vashchenko, and T. I. Vakulskaya, J. Mol. Struct. 1180, 272 (2019).
69. G. F. Prozorova, S. A. Korzhova, T. V. Kon'kova, A. S. Pozdnyakov, T. G. Ermakova, T. V. Fadeeva, S. A. Vereshchagina, and B. A. Trofimov, Russ. Chem. Bull. 60, 671 (2011).

70. G. F. Prozorova, A. S. Pozdnyakov, N. P. Kuznetsova, S. A. Korzhova, A. I. Emel'yanov, T. G. Ermakova, T. V. Fadeeva, and L. M. Sosedova, Int. J. Nanomed. 9, 1883 (2014).

71. T. Saliev, D. M. Baiskhanova, A. Akhmetova, D. A. Begimbetova, M. Akishev, G. Kulsharova, A. Molkenov, T. Nurgozhin, T. Alekseyeva, and S. Mikhalovsky, Electromagn. Biol. Med. 38, 21 (2019).

72. A. Ivask, I. Kurvet, K. Kasemets, I. Blinova, V. Aruoja, S. Suppi, H. Vija, A. Kakinen, T. Titma, M. Heinlaan, M. Visnapuu, D. Koller, V. Kisand, and A. Kahru, PLoS ONE 9 (7), e102108 (2014).

73. A. Avalos, A. I. Haza, and P. Morales, Folia Biol. 61 33 (2015).

74. C. Bacali, I. Baldea, M. Moldovan, R. Carpa, D. E. Olteanu, G. A. Filip, V. Nastase, L. Lascu, M. Badea, M. Constantiniuc, and F. Badea, Clin. Oral Investig. 24, 2713 (2020).

75. M. A. Novikov, E. A. Titov, V. Vokina, N. L. Yakimova, L. M. Sosedova, S. A. Korzhova, A. S. Pozdnyakov, and G. F. Prozorova, Acta Biomed. Scientifica, No. 2 (2), 121 (2012).

76. G. F. Prozorova, A. S. Pozdnyakov, S. A. Korzhova, M. A. Novikov, E. A. Titov, and L. M. Sosedova, Russ. Chem. Bull. 63 (9), 2126 (2014).

77. L. M. Sosedova, M. A. Novikov, and E. A. Titov, Toksikol. Vestn. 141 (6), 48 (2016).

78. M. A. Novikov, E. A. Titov, V. A. Vokina, and L. M. Sosedova, Acta Biomed. Scientifica 3 (6), 150 (2018).

79. L. M. Sosedova, M. A. Novikov, E. A. Titov, A. S. Pozdnyakov, S. A. Korzhova, and G. F. Prozorova, Pharm. Chem. J. 52 (11), 912 (2019).

80. E. S. Morozkin, I. A. Zaporozhchenko, M. V. Kharkova, A. V. Cherepanova, P. P. Laktionov, V. V. Vlasov, B. G. Sukhov, G. F. Prozorova, B. A. Trofimov, M. V. Khvostov, and T. G. Tolstikova, Chem. Sustainable Dev. 21, 147 (2013).

81. V. V. Zverev, B. F. Semenov, and R. M. Khaitov, Vaccines and Vaccination: National Guide (GEOTAR-Media, Moscow, 2011) [in Russian].

82. N. V. Medunitsin, Vaccinology (Triada-Kh, Moscow, 2010) [in Russian].

83. R. V. Petrov and R. M. Khaitov, Immunogens and Vaccines of the New Generation (GEOTAR-Media, Moscow, 2011) [in Russian].

84. T. I. Nemirovskaya, V. P. Kovtun, M. V. Abramtseva, N. V. Aleksandrova, A. P. Tarasov, R. D. Salakhova, V. A. Volkov, and V. A. Merkulov, Bioprep.: Profil., Diagn., Lech. 51 (3), 19 (2014).

85. V. S. Smirnov, Prevention and Treatment of Influenza and Acute Respiratory Viral Infections (AISING, St. Petersburg, 2012) [in Russian].

86. V. I. Dubrovina, S. A. Vityazeva, Zh. A. Konovalova, T. P. Starovoitova, G. B. Mukhturgin, B. G. Sukhov, 
G. F. Prozorova, and G. P. Aleksandrova, Nanotekhnol. Okhr. Zdorov'ya 4 (3) (2012).

87. S. A. Vityazeva, T. P. Starovoitova, V. I. Dubrovina, and Zh. A. Konovalova, Byull. VSNTs SO RAMN 87 (5), 103 (2012).

88. V. V. Voitkova, V. I. Dubrovina, S. A. Vityazeva, T. P. Starovoitova, and S. V. Balakhonov, Epidemiol. Vaktsinoprofil., No. 6 (2013).

89. V. V. Voitkova, V. I. Dubrovina, S. A. Vityazeva, T. P. Starovoitova, K. M. Korytov, and S. V. Balakhonov, Byull. VSNTs SO RAMN, 99 (5), 52 (2014).

90. G. F. Prozorova, S. A. Korzhova, A. S. Pozdnyakov, A. I. Emel'yanov, T. G. Ermakova, and V. I. Dubrovina, Russ. Chem. Bull. 64, 1437 (2015).

91. V. I. Dubrovina, S. V. Balakhonov, V. V. Voitkova, S. A. Vityazeva, T. P. Starovoitova, K. M. Korytov, G. F. Prozorova, G. P. Aleksandrova, and S. I. Kolesnikov, Byull. Eksp. Biol. Med. 162 (11), 621 (2016).

92. Immunomodulating Action of Metal-Containing Nanocomposites, Ed. by S. V. Balakhonov (Megaprint, Irkutsk, 2017) [in Russian].

93. V. I. Dubrovina, S. V. Balakhonov, V. V. Voitkova, S. A. Vityazeva, T. P. Starovoitova, K. M. Korytov,
G. F. Prozorova, G. P. Aleksandrova, and S. I. Kolesnikov, Bull. Exp. Biol. Med. 162 (11), 666 (2017).

94. Cellular and Humoral Immunity Factors in Anthrax Pathogenesis, Ed. by S. V. Balakhonov (INTsKhT, Irkutsk, 2018) [in Russian].

95. B. L. Cherkasskii, Epidemiology and Prevention of Anthrax (InterSEN, Moscow, 2002) [in Russian].

96. A. A. Vorob'ev and A. Yu. Mironov, Klin. Med. Annu., No. 21, 17 (2009).

97. G. G. Onishchenko, Zh. Mikrobiol., Epidemiol. Immunobiol., No. 3, 58 (2006).

98. U. K. Hahn, M. Aichler, R. Boehm, and W. Beyer, Vaccine 24 (21), 4595 (2006).

99. T. Chitlaru, O. Gat, H. Grosfeld, I. Inbar, Y. Gozlan, and A. Shafferman, Infect. Immun. 75 (6), 2841 (2007).

100. R. J. Cybulski, Jr., P. Sanz, and A. D. O'Brien, Mol. Aspects Med. 30 (6), 490 (2009).

101. S. Jesus and O. Borges, World J. Vaccines, No. 1, 79 (2011).

102. P. Yu. Popova and N. I. Mikshis, Zh. Mikrobiol., Epidemiol. Immunobiol., No. 1, 79 (2016).

Translated by T. Soboleva 